\title{
ACUTE PULMONARY EMBOLISM and CHRONIC VENOUS THROMBOSIS in a POLYTRAUMA PATIENT: ROLE OF BEDSIDE ULTRASOUND
}

\section{INTRODUCTION}

Pulmonary embolism (PE) is a common complication in polytraumatic patients due to the hypercoagulability state as well as immobilization. It is considered the third cause of mortality in a traumatic patient who survives 24 hours to an accident.

Diagnosis is rare in the initial evaluation of the patient.

We describe the case of a patient with PE presumably due to traumatic thrombus release in the same anatomical area where chronic deep vein thrombosis (DVT) was present.

The importance of early diagnosis of PE and / or DVT by bed-side ultrasound leading to the therapeutic implications is emphasized.

\section{CASE DESCRIPTION}

51-year-old male. No medical history apart from old right knee surgery.

High speed motorcycle accident. When arriving to polytraumatic patient box: Glasgow Coma Scale 15, hemodynamically stable and eupneic, SaO2 100\% (FiO2 $0.35 \%)$.

Blood tests:

Arterial blood gas: $\mathrm{pH} 7.40, \mathrm{PaO} 2135 \mathrm{mmHg}, \mathrm{PaCO} 2$

$33 \mathrm{mmHg}$, bicarbonate $23 \mathrm{mmol} / \mathrm{L}$.

\section{Radiology:}

CT-scan carried out in 20 minutes: acute pulmary thromboemlism with affectation of lobar branches of the right lower lobe, diastase of pubic symphysis with dislocation of right sacroiliac joint.

Conventional X-ray study: bifocal fracture of right femoral diaphysis.

Venous echography: signs of chronic thrombosis in the distal third of the superficial femoral vein and the popliteal vein on the right side. Normal left side scan.

Pulmonary echography. Echographic signs included A-lines pattern with lung sliding present.

Osteotaxis of the pelvis and femoral traction were urgently performed.

A vena cava filter was placed

In subsequent surgeries: endomedullary nail in femur and osteosynthesis with pubic symphysis plate and sacroiliac screws.

After 10 days, Tinzaparin was initiated at a dose of $175 \mathrm{lU} / \mathrm{kg}$. (anticoagulant doses).

Echocardiography was performed some days later with no signs of pulmonary hypertension.

Good clinical evolution of the patient with subsequent transfer to a rehabilitation center where still remains.

After 90 days IVC filter was removed and anticoagulation was continued for 6 months.

Fig 1: x-ray showing a
fracture of femoral
diaphysis
Fig 2:Echography
showing hiperecoic
material in popliteal vein
Fig 3: Placement of
inferior vena cava filter
Fig 4: Osteotaxis of the
pelvis placed
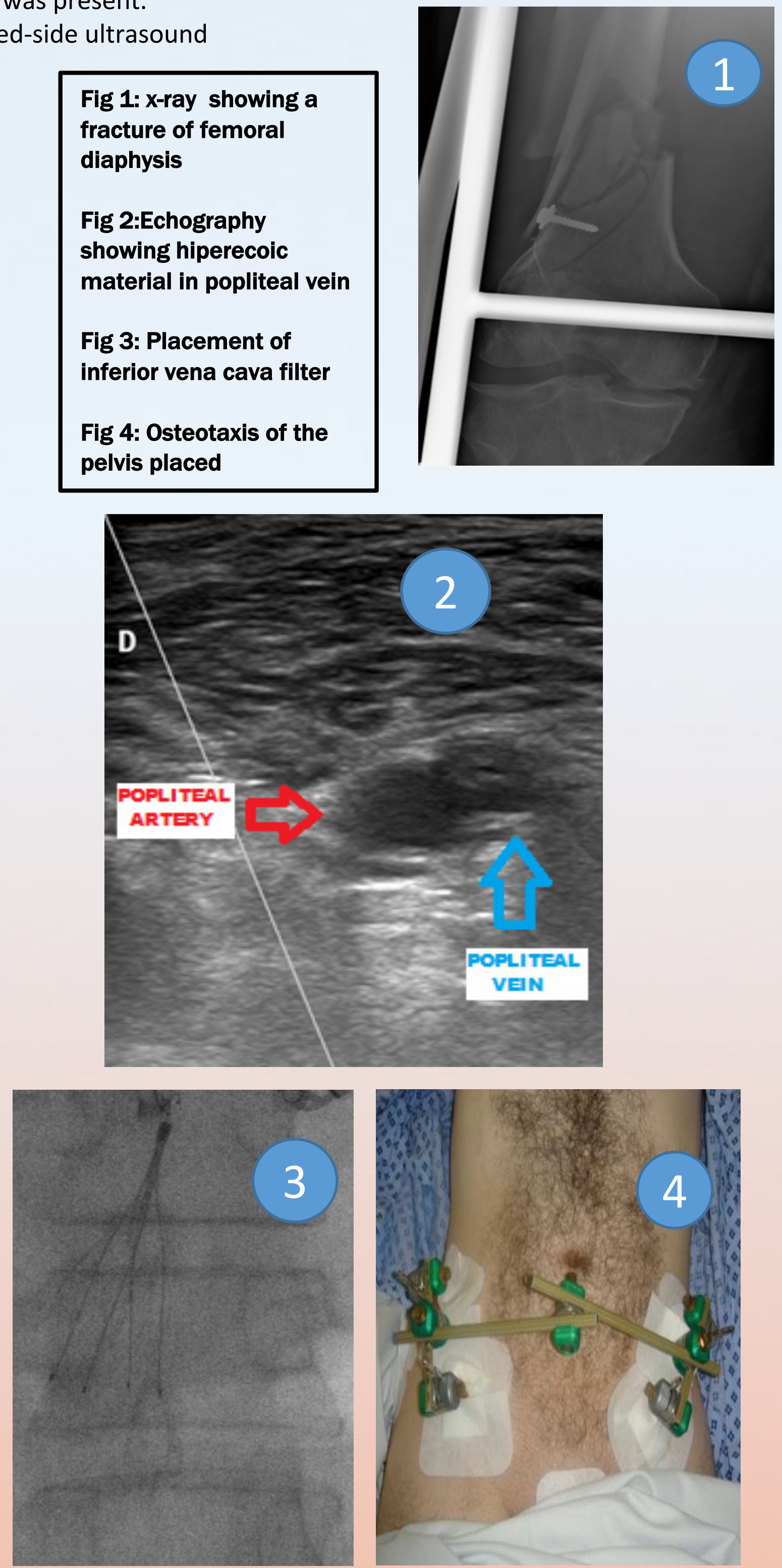

\section{DISCUSSION}

Diagnosis of TEP immediately after polytraumic event is unusual. Its presence led us to investigate whether there was an associated DVT, which may have been the cause of the PE.

Ultrasound allows the early diagnosis of different life-threatening entities in a polytraumatic patient. In our patient, chronic DVT was observed, which has therapeutic implications.

Impossibility of immediate anticoagulation led us to insert an inferior vena cava filter. Once the risk of bleeding was decreased, anticoagulation therapy was initiated.

$\underline{\text { References }}$

1.- Mabrouk B, Chaari A, Post-traumatic pulmonary embolism in the intensive care unit. Ann Thorac Med 2011 Oct-Dec; 6(4): 199-206

2.- Ruddy JM, Curry NS, Incidental pulmonary embolism identified on chest CT during initial trauma evaluation. Am Surg. 2008 Dec;74(12):1146-8

3.- Swami U, Annunziata G, Experience with vena cava filters at a large community hospital and level-I trauma center:indications, complications and compliance barrierrs. Clin Appl Thromb Hemost. $2014 \mathrm{Jul} ; 20(5): 546-52$ 